\title{
Poverty: A clinical instrument for family physicians
}

\author{
Gayathri Sivakumar, Brandon Chau \\ Faculty Reviewer: Thomas Freeman, MD, MCISc, CCFP, FCFP (Department of Family Medicine)
}

\begin{abstract}
The primary driver of health outcomes is not medical professionals and the treatment they provide, but rather the socioeconomic environments enveloping individuals from the time they are born until their last breath. Social determinants of health (SDOH), which are factors such as income, education, ethnicity, disability, and access to healthcare, create disparities in morbidities and mortalities across a social gradient. Poverty constitutes one of the most well-studied and well-acknowledged SDOH, with a wide-ranging and treacherous impact on one's health and well-being. A new poverty tool, created by the College of Family Physicians of Canada and the Centre for Effective Practice, enables front-line clinicians to tackle the social challenges associated with a low socioeconomic status. Consideration of socioeconomic conditions in a clinical practice setting can improve health outcomes by optimizing clinical management decisions and reduce the burden on our healthcare system.
\end{abstract}

\section{INTRODUCTION}

Case study: Amanda is a 38-year old single mother of three kids. She has a history of smoking 10-pack-years. In addition to being on income support, Amanda works as a maid and laundry worker at a motel for minimum wage and works extremely long hours. She has a Grade 7 education. Amanda lacks family and community support. She has a history of abuse by alcoholic parents. Amanda rarely visits a family doctor because of her childcare duties and inability to take time off from work. She presented to the emergency room suddenly and was diagnosed with Stage IVB metastatic cervical cancer. Sadly, she passed away within two months of her diagnosis.

While the official cause of Amanda's death was her cancer, could the real culprit of her demise be related to her status of poverty?

The evidence supporting the link between health status and disease burden to a social gradient can be traced back to the early 1800s and continues to become more powerful. ${ }^{1,2}$ Inequalities in the distribution of income, power, and resources patently contribute to the growing disparities in health outcomes amongst Canadians. SDOH contribute to one's socioeconomic status (SES) and are living conditions that shape the health and well-being of individuals and communities. The SDOH include, but are not limited to early-childhood development, income, education, ethnicity, gender, sexuality, Indigenous status, immigration status, and access to the healthcare system. ${ }^{3,4}$

\section{POVERTY AS A CLINICAL TOOL TO IDENTIFY RISK FACTORS IN PRIMARY CARE}

Poverty has been demonstrated to be a health risk comparable to smoking, hypertension, and high cholesterol levels. ${ }^{5}$ Living in poverty has been inextricably tethered to a higher risk for chronic diseases including diabetes, cardiovascular disease, stroke, respiratory illnesses, nervous system disorders, alcoholic cirrhosis, mental illnesses, accidents, and trauma. ${ }^{5-9} \mathrm{~A}$ study assessing trends in mortality demonstrated that income accounts for $24 \%$ of potential years of life lost in Canada. ${ }^{7}$ In Hamilton, ON, there is a gap of 21 years in the average age at death between the residents of highest- and lowest-income neighborhoods. ${ }^{10}$ Moreover, those who are chronically homeless are at 8-10 $\times$ greater risk for premature death in comparison to the general population. ${ }^{3-5}$

For those with a lower SES, barriers to housing, food security, education, employment, and physical and mental well-being become more significant. ${ }^{3}$ For instance, in contrast to the richest of Ontarians, the poorest report higher rates of smoking and physical inactivity, reduced fruit and vegetable intake, and increased incidences of multiple chronic disorders. ${ }^{5}$ Lower SES is also associated with reduced access to quality healthcare services. ${ }^{5}$ Inequitable access to healthcare diminish the opportunity for routine checkups including recommended screenings such as pap smears, hinder health education, early diagnosis, and clinical management of an illness, and ultimately contribute to the perpetuation of poor health outcomes. Reduced accessibility to healthcare further prompts a higher proportion of emergency room visits and hospitalizations for conditions that could be well-managed in a community clinic, contributing to a greater economic burden. ${ }^{5}$

\section{ADDRESSING POVERTY IN A CLINICAL ENCOUNTER}

Family physicians, being providers of comprehensive and longitudinal care, are in an unparalleled position to address poverty in their practices. ${ }^{11}$ However, according to a qualitative study, family physicians feel ill-prepared in confronting poverty needs in clinical encounters. ${ }^{12}$ Just as one would screen for diabetes, hypertension, and cardiovascular disease, there is a need for a systematic way to screen for poverty that would help health care providers recognize socioeconomic inequities within their practice populations, enable better patient-centered care for the disadvantaged, and reduce their health risks and related unfavourable health corollaries. ${ }^{11}$

In order to develop an effective clinical intervention to address challenges related to SDOH in primary care, the College of Family Physicians of Canada (CFPC) collaborated with the Centre for Effective Practice (CEP) to establish and distribute province-specific poverty tools across Canada. ${ }^{13}$ This poverty tool includes three systematic steps to address poverty in a clinical encounter. 
Step \#1. Screen for Poverty. It is imperative to screen everyone for the poverty risk factor. Brcic et al (2011) developed an evidence-based poverty case-finding tool that can be used by family physicians to identify patients who are poor. A simple question, "Do you (ever) have difficulty making ends meet at the end of the month?", was identified to be a good screening tool for poverty with a sensitivity of $98 \%$ and a specificity of $64 \% .{ }^{11}$ If the answer is yes, then the physician can proceed with Step \#2.

Step \#2. Adjust for Risks. Physicians must acknowledge that women, Indigenous populations, newcomers, visible minorities, and the LGBTQ+ communities are among the highest risk groups for a wide range of chronic conditions. ${ }^{13,14}$ In addition, family physicians need to have a general understanding that when it comes to patients in poverty, regardless of their risk profile, they are at an elevated risk for health conditions such as cardiovascular disease, diabetes, depression, and suicidal ideation. ${ }^{14}$ Experiencing poverty is also associated with other chronic conditions such as high blood pressure, inflammatory disorders, and chronic obstructive pulmonary disease. ${ }^{14}$

Step \#3. Ask, Educate, and Intervene/Connect. Family physicians should ask probing questions to understand the patient's living situation, financial burdens, employment, social assistance and supports, and the remunerations they receive from the government. Depending on the patient's needs and living conditions, family physicians can direct patients to allied health professionals such as social workers to be educated on topics such as tax returns, income supplements, drug coverages, child and disability benefits, and non-insured health benefits for First Nations. Physician intervention and the dialogue that this generates with patients and their families can identify opportunities for additional income and benefits support, and connect patients to government and community resources. ${ }^{14}$

The poverty tool places family physicians vis-à-vis with the threats posed by poverty. Using the poverty tool can empower physicians to take on more of a leadership and advocacy role within their clinical encounters, and more importantly, present patients with opportunities to access appropriate and available resources, ultimately fostering a more positive socioeconomic environment in their lives.

\section{IMPLICATIONS OF POVERTY TOOLS IN MEDICINE}

The use of poverty tools to modify clinical decision-making reflects a drastic cultural shift in the field of medicine, from a strict biomedical approach to one that takes into account patient context. ${ }^{15}$ In Ontario, the Ontario College of Family Physicians (OCFP) Poverty and Health Community of Practice, an association of primary care providers dedicated to reducing health disparities, continues to mediate discussions related to poverty and associated adverse health outcomes across the province. ${ }^{14}$ OCFP has been actively engaged in anti-poverty advocacy projects, emphasizing the commitment of medical professionals towards social accountability. ${ }^{14,15}$ OCFP has been accentuating the intensifying duty for family physicians to regard poverty as an avertible and treatable condition and that family physicians are in a unique position to combat poverty. ${ }^{14}$

The CFPC recognizes that aside from advocacy at the micro-level in the clinic, physicians can also become activists at the meso-level in the local community and at the macro-level. ${ }^{15}$ At the meso-level, family physicians can collect and use community-level data on SDOH to educate and train health care professionals. ${ }^{15}$ This information can also be used to understand the health needs of the local community and identify gaps in the provision of care. In addition, physicians can provide on-site healthcare services to patients that are unable to visit the clinic. ${ }^{15}$ At a macro-scale, family physicians can initiate collaborations with organizations to advocate for improved living conditions for the general Canadian population and advocate for the transformation of public health policies that target upstream elements of health such as benefits, social assistance, and affordable housing. ${ }^{15}$

\section{SUMMARY}

Poverty has a powerful impact on health outcomes and creates inequities in health outcomes between the highest- and lowest-income populations. For decades, what has been considered as a social issue now needs to be perceived as a health issue. The poverty screening and intervention tools developed by the CFPC and CEP empower family physicians to take a stand against poverty, help guide clinical action to provide the best possible patient outcomes, and tackle the social challenges faced by those who are living in poverty. Amanda, who was presented in the case study at the beginning of our article, would have been identified as an individual of low socioeconomic status by her doctor, who then may have been able to accommodate Amanda's work schedule for her routine appointments. Amanda could have gotten her pap smear and she could have become educated about tax benefits, income supplementation, and government grants. She could have survived and lived a long, healthy life.

While further evidence is required to optimize the screening, risk-assessment, and intervention practices, integration of poverty as a clinical tool in medical practice is a step in the right direction for family physicians to become more socially accountable. With more family physicians adopting poverty as a health risk, those from marginalized populations can begin to receive more accessible and appropriate care.

\section{REFERENCES}

1. McKeown T, Record RG. Reasons for the decline of mortality in England and Wales during the nineteenth century. Popul Stud. 1962;16:94-122.

2. Logan WPD. Mortality in England and Wales from 1848 to 1947. Popul Stud. 1950;4:132-78.

3. Raphael D. Social determinants of health: Canadian perspectives, 2nd edition. Toronto: Canadian Scholars' Press; 2009.

4. Mikkonen J, Raphael D. Social determinants of health: The Canadian facts. Toronto: York University School of Health Policy and Management; 2010. 
5. Income and Health: Opportunities to achieve health equity in Ontario. Health Quality Ontario. Toronto: Queen's Printer for Ontario; 2016.

6. Improving the health of young Canadians. Canadian population health initiative. Ottawa: Canadian Institute for Health Information; 2005.

7. Wilkins R, Berthelot JM, Ng E. Trends in mortality by neighbourhood income in urban Canada from 1971 to 1996. Ottawa: Statistics Canada; 2002.

8. Emerson E. Relative child poverty, income inequality, wealth, and health. JAMA. 2009;301(4):425-6.

9. Currie J, Lin W. Chipping away at health: more on the relationship between income and child health. Health Affairs. 2007;26(2):331-44.

10. Hamilton Spectator [Internet]. Worlds Apart. Hamilton (ON): Hamilton Spectator; 2010 Aug [cited 2017 May 26]. Available from: http:// www.thespec.com/news-story/2168237-worlds-apart.

11. Brcic V, Eberdt C, Kaczorowski J. Development of a tool to identify poverty in a family practice setting: a pilot study. Int J Family Med. 2011 May; Article ID: 812182.

12. Willems SJ, Swinnen W, DeMaeseneer JM. The GP's perception of poverty: a qualitative study. Family Practice. 2005;22(2):177-83.

13. TheWell [Internet]. Poverty: A Clinical Tool For Primary Care Providers. Toronto: Centre for Effective Practice; 2016 Nov [cited 2017 Apr 23]. Available from: https://thewellhealth.ca/wp-content/uploads/2016/12/Poverty_flow-Tool-Final-2016v4.pdf.

14. Ontario College of Family Physicians [Internet]. Primary Care Interventions in Poverty. 2016 [cited 2017 Apr 23]. Available from: http:// ocfp.on.ca/cpd/povertytool.

15. Patient's Medical Home [Internet]. Best Advice - Social Determinants of Health. College of Family Physicians of Canada; 2015 Mar [cited 2017 Apr 23]. Available from: http://patientsmedicalhome.ca/files/uploads/BA_SocialD_ENG_WEB.pdf. 